\title{
Trends and causes of maternal mortality in Eastern province of Turkey
}

\author{
Numan Çim ${ }^{1^{\star}}$, Erkan Elçi ${ }^{2}$, Sena Sayan ${ }^{2}$, Gülhan Guneş Elçi ${ }^{2}$, Şerif Aksin ${ }^{3}$, Recep Yıldızhan ${ }^{1}$ \\ ${ }^{1}$ Y uzuncu Yil University Faculty of Medicine, Department of Obstetric and Gynecology, Van, Turkey \\ ${ }^{2}$ Clinic of Gynecology and Obstetrics, Van Education and Research Hospital, Ministry of Health of The Turkish \\ Republic, University of Health Sciences, Van, Turkey \\ ${ }^{3}$ Clinic of Gynecology and Obstetrics, Diyarbak.r Gazi Yasargil Education and Research Hospital, Ministry of Healt h of \\ The Turkish Republic, University of Health Sciences, Diyarbakir, Turkey
}

\begin{abstract}
We aimed to analyse causes of maternal mortality cases in Eastern province of Turkey.

Maternal mortality cases were retrospectively investigated. The cases were evaluated for age, gravida, age at first birth, gestational week, postpartum death time, educational status, illnesses in their history, high risk pregnancies, pregnancy termination type, delivery methods and death causes. The distribution of these cases by type of death and years is examined. In addition, the causes of death were compared among groups according to their death pattern and years.

A total of 69 maternal deaths were detected between January 2010 and December 2016. The maternal mortality rate was 20.1 per, 100000 livebirths. The mean age of the cases was $30.4 \pm 7.6$ and they had their first births when they were $20.9 \pm$ 5.1 years old. Mean number of gravida was $3.9 \pm 2.8$. These cases were $32.3 \pm 7.4$ in the week of gestation when mortality occurred. The mean number of pregnancy follow-ups was $4.24 \pm 4.0$, postpartum direct maternal mortality time was $13.7 \pm$ 25.5 days.

The number of maternal mortality according to the years was respectively; $6,12,15,16,7,13$.

When the causes of maternal mortality are examined; $26.1 \%$ of the cases had preeclamptic diseases, $15.9 \%$ had hemorrhage, $10.1 \%$ committed suicide, $8.7 \%$ had pulmonary embolism, $7.2 \%$ had cerebrovascular disease, $5.8 \%$ had heart disease, $5.8 \%$ had amnion fluid embolism, $4.3 \%$ had sepsis, $4.3 \%$ had traffic accidents, $4.3 \%$ had firearm injuries, $2.9 \%$ had malignancy, $1.4 \%$ had pneumonia, $1.4 \%$ had multiple organ failure, and $1.4 \%$ had died due to electric shock. Among the direct causes of death; preeclamptic diseases, hemorrhage and pulmonary embolism were the most common and among the causes of indirect death; cerebrovascular diseases, heart diseases and sepsis were the most common.

Maternal mortality is an important obstetric complication that needs to be paid attention to. Preeclamptic diseases and hemorrhage continue to be the most common cause of maternal mortality.
\end{abstract}

Key Words: Maternal mortality, preeclampsia, haemorrhage

\section{Introduction}

Pregnancy and the birth following it are important and happy events for parents. But this happy event sometimes doesn't end in the physiological normal course of life, and causes great sadness to the family and the social environment. One of these terrible consequences is maternal mortality. Maternal mortality is the mother's death during pregnancy or within 42 days of birth (1). If there is a maternal complication related to the pregnancy, it is assumed that it will occur in this period. However, if there is a negative medical or mental health condition, these complications will continue more than 42 days. Maternal deaths can be seen from 42 days after birth to 1 year after birth due to adverse health conditions accompanying many pregnant women (cardiovascular diseases, etc.) (2). This situation is called late maternal mortality. One of the most important indicators of development level of a country is maternal mortality. According to World Health Organization (WHO) data; around 830 women die every day from complications related to pregnancy or birth. Most of these deaths occur in low-income areas and most of these deaths are due to preventable causes. These include; hemorrhage, hypertension, infection and indirect causes. The risk of maternal mortality in developing countries is 33 times higher than in the developed countries $(3,4)$.

In the Millennium Development Goals report, WHO has recommended that Member States reduce maternal mortality by $75 \%$. According to estimates made by WHO in 2015, maternal mortality declined by $44 \%$ globally over the years 
1990-2015. But despite this progress, the maternal mortality rate in Sub-Saharan African countries continue to remain high $(5,6)$. The maternal mortality rate in Turkey is reported to be 28.5 per 100.000 live births (7).

The causes of maternal mortality are divided as direct and indirect causes. Obstetric complications are the direct causes. Preeclampsia, placental ablation, etc. situations are examples for direct reasons. The indirect causes are not caused by pregnancy but happens before or during pregnancy and pathophysiology of pregnancy worsens the situation. Maternal heart diseases, pneumonia etc. diseases can be cited as examples (8).

\section{Materials and methods}

This study was done using data from Van Public Health Directorate Noncontagious Disease Division, Maternal Mortality Review Commission. In the study, maternal mortality cases between January 2010 and December 2016 were investigated. After the earthquakes which occurred in October and November 2011 in Van province, as a precaution, due to citizens' evacuation to other cities for a period of time, data from 2011 could not be reached.

Maternal mortality is defined as maternal death occurring during pregnancy, childbirth or the next 42 days after birth. Deaths up to 1 year from postpartum 42 nd day were also defined as late maternal mortality. Maternal death cases that fit to this definition were included in the study. Maternal death cases outside of this definition were excluded from the study. The file information of the cases in the study group was evaluated retrospectively. MMR was calculated as the number of maternal deaths in 100.000 live births. All cases were evaluated for age, gravida, age at first birth, gestational week, postpartum death time, educational status, history of illness, presence of high risk pregnancy, pregnancy termination type, delivery method and death cause. The distribution of these cases by type of death (random, direct and indirect maternal mortality) and years was examined. In addition, the causes of death were compared among groups according to their death pattern and years.

The study included cases of maternal mortality between January 2010 and December 2016.

Statistical Analysis: In our study, descriptive statistics for continuous variables are expressed as Mean, Standard Deviation, Minimum and
Maximum values; expressed as Number and Percentage for categorical variables. Chi-square test was used to determine the relationship between groups and categorical variables. The statistical significance value was taken as $\leq 5 \%$ in the calculations and the statistical package program of SPSS (IBM SPSS for Windows, ver.23) was used for the calculations.

\section{Results}

Between January 2010 and December 2016, a total of 69 maternal deaths were detected. The maternal mortality rate was 20.1 per, 100000 livebirths (Table 1). The birth rate in Van is given in Figure 1.

The demographic characteristics of cases with maternal mortality are given in Table 2 . The mean age of the cases was found to be $30.4 \pm 7.6$ and the first births were in $20.9 \pm 5.1$ years. Mean gravida numbers were $3.9 \pm 2.8$. These cases were $32.3 \pm 7.4$ in the week of gestation when mortality occurred. The average number of pregnancy follow-ups in these cases was $4.24 \pm$ 4.0. The mean maternal mortality time for these cases was $13.7 \pm 25.5$ days. The educational status of the cases is given in Table 3 . When educational status was examined, it was found that $46.4 \%$ (32) were not literate.

The history characteristics of the cases are given in Figure 2. When evaluated in terms of history, $82.6 \%$ (57) of them had not shown any features.

Table 1. Maternal mortality rate according to years

\begin{tabular}{cc}
\hline Year & Maternal Mortality Rate (MMR) \\
\hline 2010 & 20.0 \\
\hline 2012 & 24.0 \\
\hline 2013 & 26.1 \\
\hline 2014 & 39.2 \\
\hline 2015 & 10.10 \\
\hline 2016 & 13.73 \\
\hline
\end{tabular}

Hypertension in 5.8\% (4), stomach ca, 2.9\% (2), other malignancies in $2.9 \%$ (2), cerebral infarct in $1.4 \%$ (1), brain tumor in $1.4 \%$ (1), sickle cell anemia in $1.4 \%(1)$, and myasthenia gravis in $1.4 \%$ (1) of patients had been seen.

$30.4 \%$ (21) of maternal mortalities were high-risk pregnancies and $69.6 \%$ (48) had no high-risk pregnancies (Table 4). 
The termination way of the pregnancies of the cases is given in Figure 3. 53.6\% (37) had a cesarean delivery, $27.5 \%$ (19) had vaginal delivery, $1.4 \%$ (1) had abortion and $17.4 \%$ (12) had died before the end of pregnancy.

The numbers of maternal mortality according to years are given in Figure 4. In 2010 mortality occurred in 6 cases, these numbers were 12 in 2012, 15 in 2013, 16 in 2014, 7 in 2015 and 13 in 2016.

The mortality causes of the cases are given in Figure 5. 17.4\% (12) had incidental death, 58.0\% (40) had direct death, 24.6\% (17) had indirect death.
Table 2. Demographic characteristics of the cases

\begin{tabular}{lc}
\hline & $\begin{array}{c}\text { Mean } \pm \text { SD } \\
(\mathrm{n}: 69)\end{array}$ \\
\hline Age (year) & $30.4 \pm 7.6$ \\
Age at first birth (year) & $20.9 \pm 5.1$ \\
$\begin{array}{l}\text { Gravida } \\
\text { Pregnancy week }\end{array}$ & $3.9 \pm 2.8$ \\
$\begin{array}{l}\text { The number of cases in the } \\
\text { follow-up pregnancy }\end{array}$ & $4.3 \pm 7.4$ \\
$\begin{array}{l}\text { Postpartum maternal death time } \\
\text { (days) }\end{array}$ & $13.7 \pm 25.5$ \\
\hline
\end{tabular}

The data are given as mean \pm SD (standard deviation).

Table 3. Educational situations of the cases

\begin{tabular}{lc}
\hline & $\begin{array}{c}\text { The number and } \\
\text { percentage of cases }(\mathrm{n}, \%)\end{array}$ \\
\hline Non-literate & $32(46.4 \%)$ \\
Literate & $10(14.5 \%)$ \\
Elementary school & $21(30.4 \%)$ \\
High school & $4(5.8 \%)$ \\
University & $2(2.9 \%)$ \\
\hline Total & $69(100 \%)$ \\
\hline
\end{tabular}

The data are given in numbers and percentages.

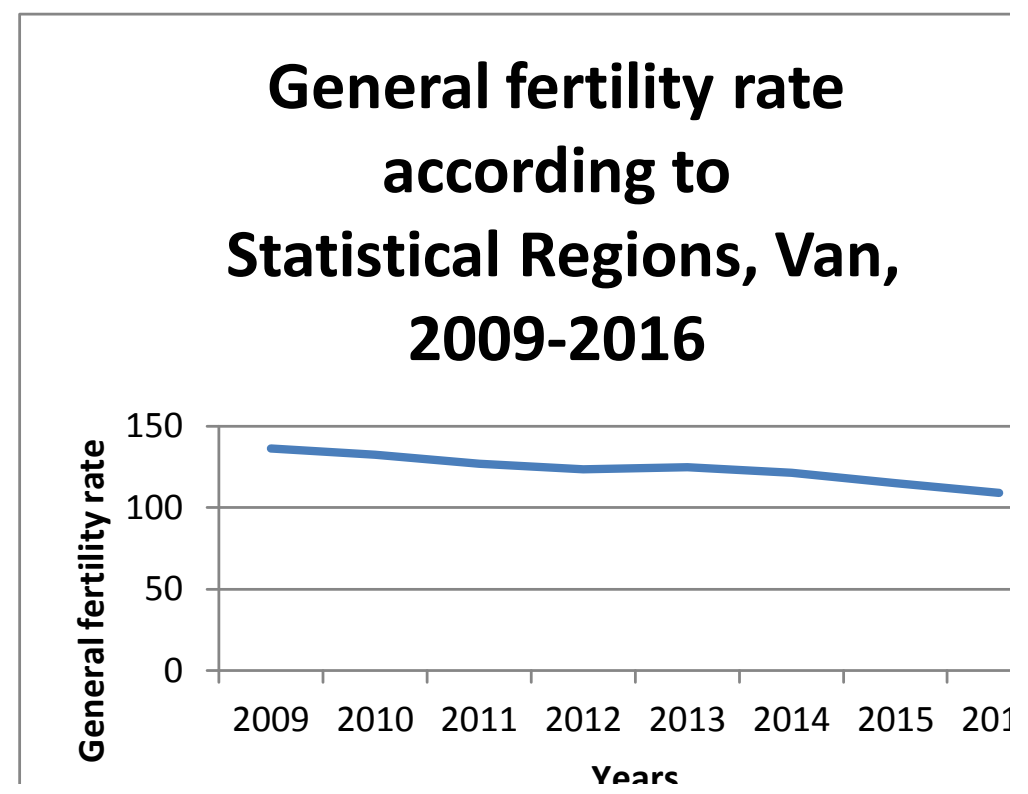

Fig. 1. General fertility rate by Statistical Regions, Van, 2009-2016 Source: General Directorate of Civil Registration and Nationality (r) Birth data were revised with updated administrative records (9). 


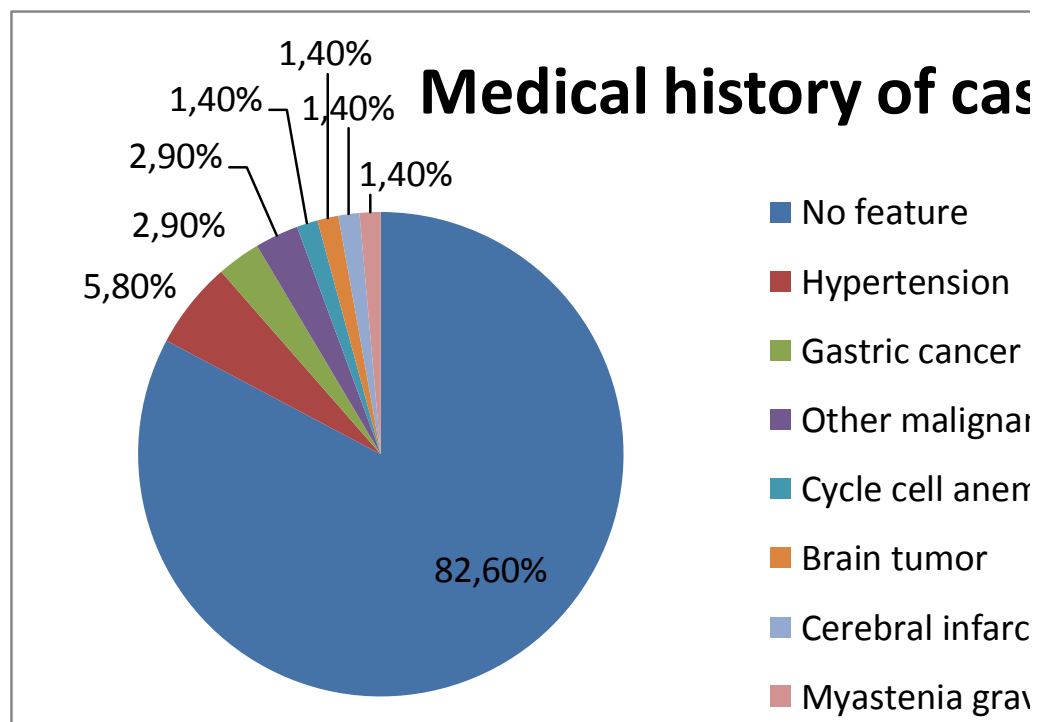

Fig. 2. Medical history of the cases.

The data are given in percent $(\%)$.

Table 4. Pregnancy characteristics of the cases

\begin{tabular}{lc}
$\begin{array}{l}\text { High-risk } \\
\text { pregnancy }\end{array}$ & $\begin{array}{c}\text { The number and } \\
\text { percentage of cases }(\mathrm{n}, \%)\end{array}$ \\
\hline No & $48(69.6 \%)$ \\
Yes & $21(30.4 \%)$ \\
\hline Total & $69(100)$ \\
\hline
\end{tabular}

The data are given in numbers and percentages.

When the causes of maternal mortality examined in general; $26.1 \%$ (18) of cases were due to preeclamptic diseases, $15.9 \% \quad$ (11) were hemorrhagic cases, $10.1 \%$ (7) were suicide cases, $8.7 \%$ (6) were pulmonary embolisms, 7.2\% (5) were cerebrovascular diseases, $5.8 \%$ (4) were amnion fluid embolism, 4.3\% (3) were sepsis, $4.3 \%$ (3) were traffic accidents, $4.3 \%$ (3) were firearm injury, \%2.9 (2) were malignancy, 1.4\% (1) was pneumonia (due to H1N1 virus), 1.4\% (1) was multi organ failure, $1.4 \%$ (1) was died due to electric shock (Figure 6).

\section{The ending of pregnancy of cases}

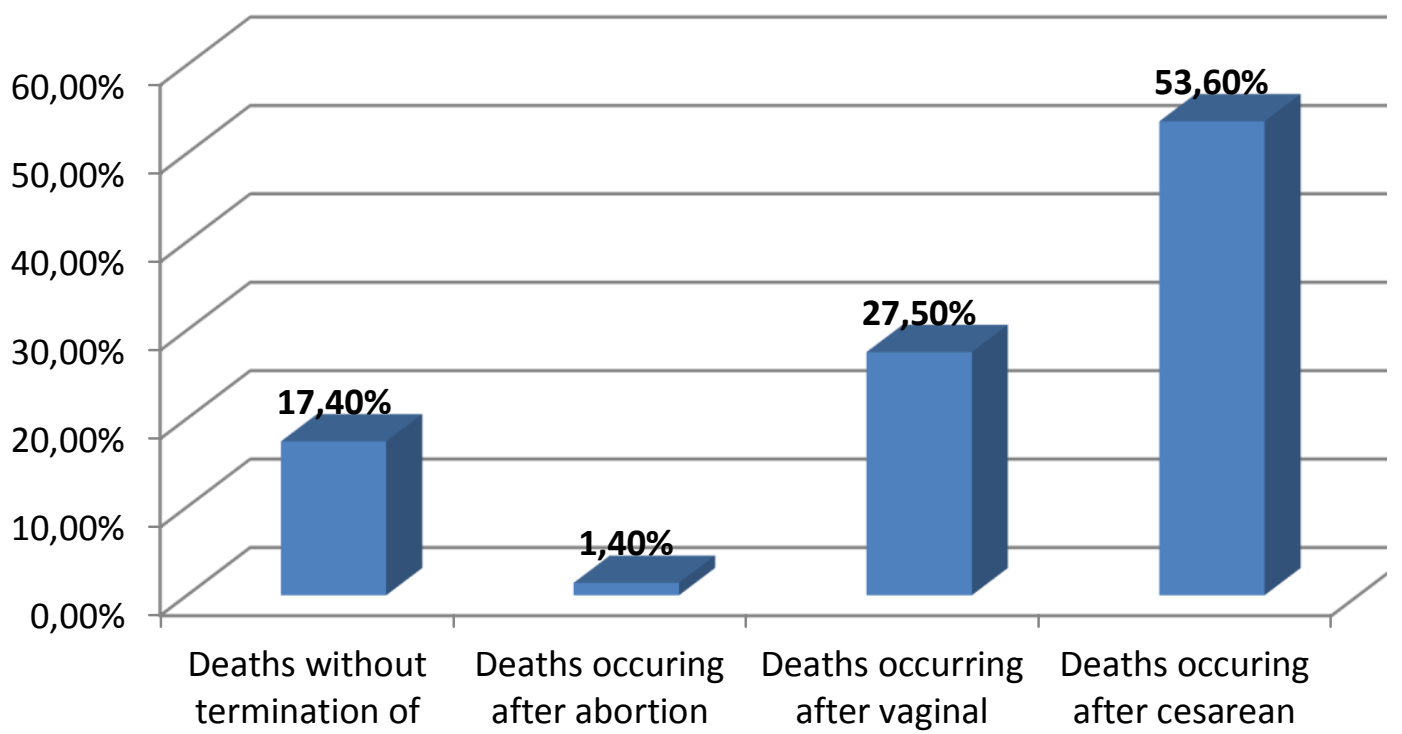

Fig. 3. The ending of pregnancy of cases

The data are given in percent $(\%)$. 


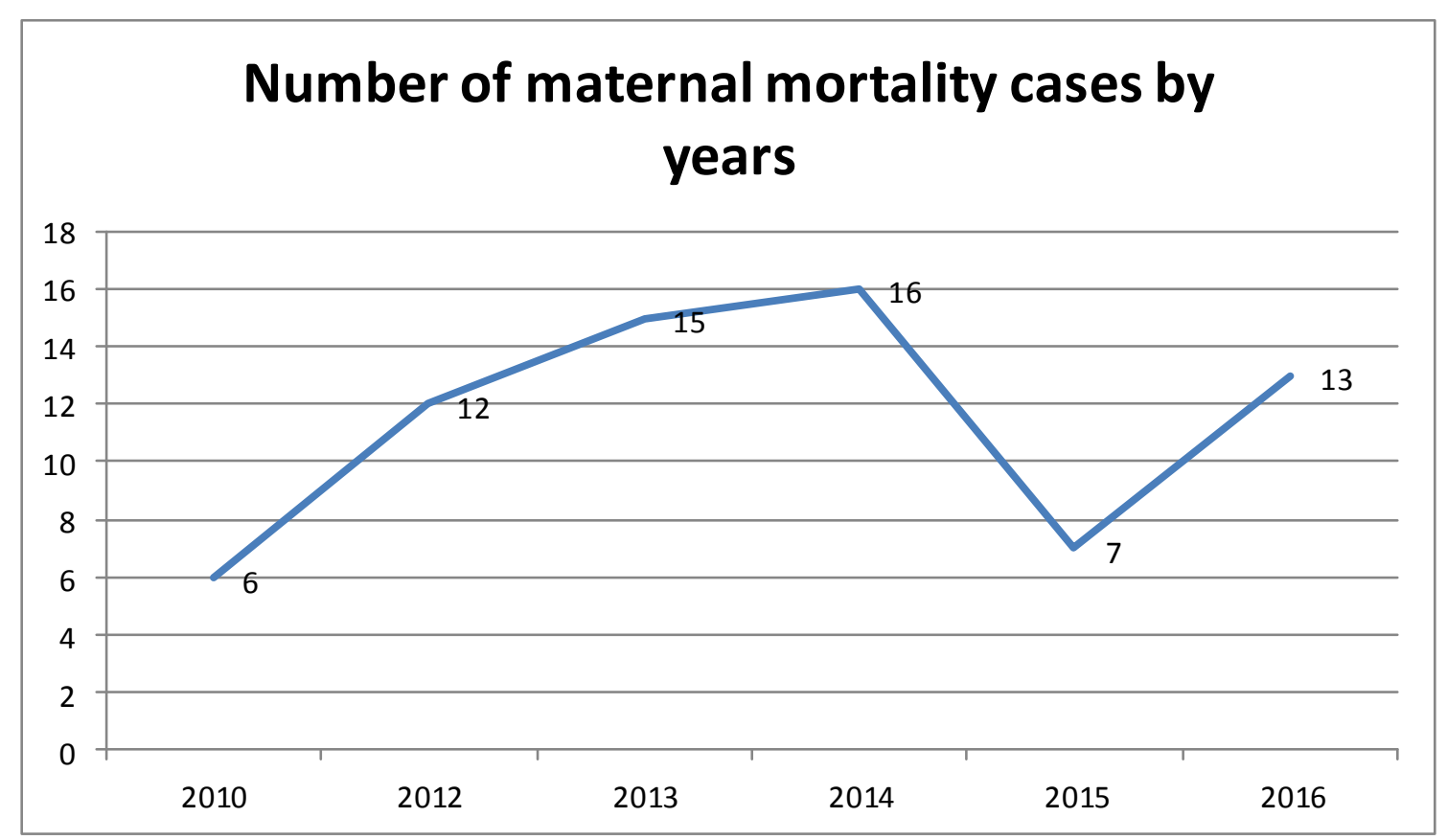

Fig. 4. Number of maternal mortality cases by years.

The data are given in number.

\section{The type of maternal mortality}

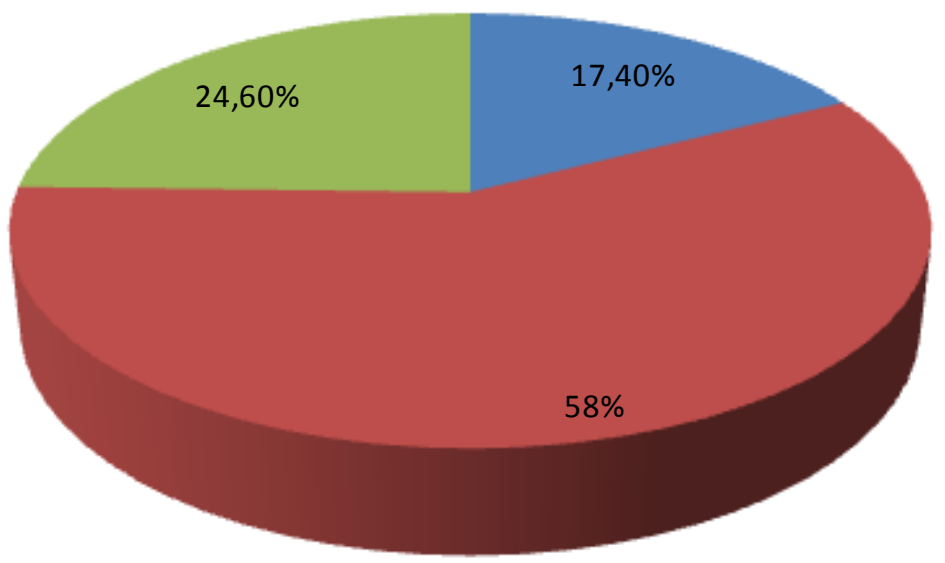

Incidental Death

Direct Death

Indirect Death

Fig. 5. The type of maternal mortality.

The data are given in percent $(\%)$.

A comparison of causes of maternal mortality is given in Table 5 . Among the causes of accidental death; suicide (41.7 \%), traffic accidents (25\%) and firearm injuries $(25 \%)$ were the most common causes.

Among the direct causes of death; preeclamptic diseases ( $45 \%$ cases), hemorrhage ( $27.5 \%$ cases) and pulmonary embolism $(15 \%$ cases $)$ were the most common causes.

Among the causes of indirect death; cerebrovascular diseases $(23.5 \%$ cases $)$, heart diseases (23.5\% cases) and sepsis (17.6\% cases) were the most common causes.

The number of maternal mortality causes according to years is given in figure 7 . 


\section{Discussion}

One of the places where fertility rate is high in Turkey is Van Province. In our study, we determined the maternal mortality rate in Van as 20.1 per, 100000 livebirths.

According to Idoko et all.'s (10) study of maternal mortality rates in Gambia, maternal mortality rates ranged from $1461 / 100.00$ to $2105 / 100.000$ per year. The major causes of maternal mortality were bleeding

(26.5\%), hypertension (19.8\%), sepsis (10.6\%) and anemia (8.6\%). Although Nigeria, one of the subSaharan countries, account for less than $2 \%$ of world population, about $10 \%$ of the world's maternal mortalities are located there. In a study conducted by Obiechina et al., (11) when maternal mortality causes were examined, it was found that $75 \%$ of cases of direct obstetric causes, $23.3 \%$ of cases of indirect obstetrics and $1.94 \%$ of coincidental cases resulted in death. Preeclampsia, bleeding, sepsis and uterine rupture were the most common direct obstetric causes of maternal mortality, respectively. In a study investigating the causes of maternal mortality in Ethiopia, it was reported that $1 / 3$ of the cases were due to direct obstetric causes such as anesthesia, complications of embolism and peripartum cardiomyopathy $(25.7 \%)$. Other causes were complications of abortus (\%19.6), maternal hemorrhage (\%12.2), hypertensive diseases (\%10.3), maternal sepsis and infections (\%9.6), HIV/AIDS (\%0.5). In the same study, when the maternal mortality due to bleeding was examined according to years, early postpartum hemorrhages were found to be the main mortality cause, although antepartum, intrapartum, early postpartum and late postpartum bleeding rates decreased over the years (12). When the causes of mortality in our study were examined, it was found that the most frequent death was direct death $(58 \%)$, as stated in the literature. Indirect deaths were detected in $24.6 \%$ of the cases and $17.4 \%$ of the cases died due to accidental deaths. When we evaluate the cases according to years, we have found that the lowest number of deaths occurred in 2010 and 2015, and the highest number of deaths occurred in 2013, 2014 and 2016 (Figure 4).

In a study of maternal mortality in the last 20 years in China, maternal mortality rate during pregnancy was $27.4 \%$ between 1996 and 2005, compared to $35.4 \%$ between 2006 and 2015. In the same study, maternal mortality was $6.2 \%$ in the intrapartum period in the first 10 years, whereas maternal mortality in the intrapartum did not occur in the last 10 years. In addition, the authors found that maternal mortality reasons varied over the last 10 years compared to the first 10 years. In the last 10 years, $63.1 \%$ of maternal mortalities were found to be due to indirect obstetric causes while $36.9 \%$ of them were due to direct obstetric reasons. Although postpartum hemorrhage is reduced, it is the most important cause of maternal mortality and other important causes are cardiac diseases and cerebrovascular diseases in this study (13).

Table 5. A comparison the type of of maternal mortality according to cause of death

\begin{tabular}{|c|c|c|c|c|c|}
\hline \multicolumn{6}{|c|}{ Type of Maternal Mortality } \\
\hline \multirow{17}{*}{ 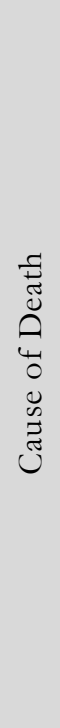 } & & $\begin{array}{c}\text { Incidental Mortality } \\
(\mathrm{n}, \%)\end{array}$ & $\begin{array}{l}\text { Direct Death } \\
(\mathrm{n}, \%)\end{array}$ & $\begin{array}{c}\text { Indirect Death } \\
(\mathrm{n}, \%)\end{array}$ & $\begin{array}{l}\text { Total } \\
(\mathrm{n}, \%)\end{array}$ \\
\hline & Preeclamptic diseases & 0 & $18(45 \%)$ & 0 & $18(26.1 \%)$ \\
\hline & Hemorrhage & 0 & $11(27.5 \%)$ & 0 & $11(15.9 \%)$ \\
\hline & Suicide & $5(41.7 \%)$ & 0 & $2(11.8 \%)$ & $7(10.1 \%)$ \\
\hline & Pulmonary embolism & 0 & $6(15 \%)$ & 0 & $6(8.7 \%)$ \\
\hline & Cerebrovascular diseases & 0 & $1(2.5 \%)$ & $4(23.5 \%)$ & $5(7.2 \%)$ \\
\hline & Heart disease & 0 & 0 & $4(23.5 \%)$ & $4(5.8 \%)$ \\
\hline & Amniotic fluid embolism & 0 & $4(10 \%)$ & 0 & $4(5.8 \%)$ \\
\hline & Sepsis & 0 & 0 & $3(17.6 \%)$ & $3(4.3 \%)$ \\
\hline & Traffic accident & $3(25 \%)$ & 0 & 0 & $3(4.3 \%)$ \\
\hline & Firearm injuries & $3(25 \%)$ & 0 & 0 & $3(4.3 \%)$ \\
\hline & Malignancy & 0 & 0 & $2(11.8 \%)$ & $2(2.9 \%)$ \\
\hline & Multi organ failure & 0 & 0 & $1(5.9 \%)$ & $1(1.4 \%)$ \\
\hline & Pneumonia (H1N1) & 0 & 0 & $1(5.9 \%)$ & $1(1.4 \%)$ \\
\hline & Electric shock & $1(8.3 \%)$ & 0 & 0 & $1(1.4 \%)$ \\
\hline & Total $(n, \%)$ & $12(100 \%)$ & $40(100 \%)$ & $17(100 \%)$ & $69(100 \%)$ \\
\hline & & $\mathrm{Ch}$ & $: 119,360$ & $\mathrm{p}: 0,0001$ & \\
\hline
\end{tabular}

The data are given in numbers and percentages. 


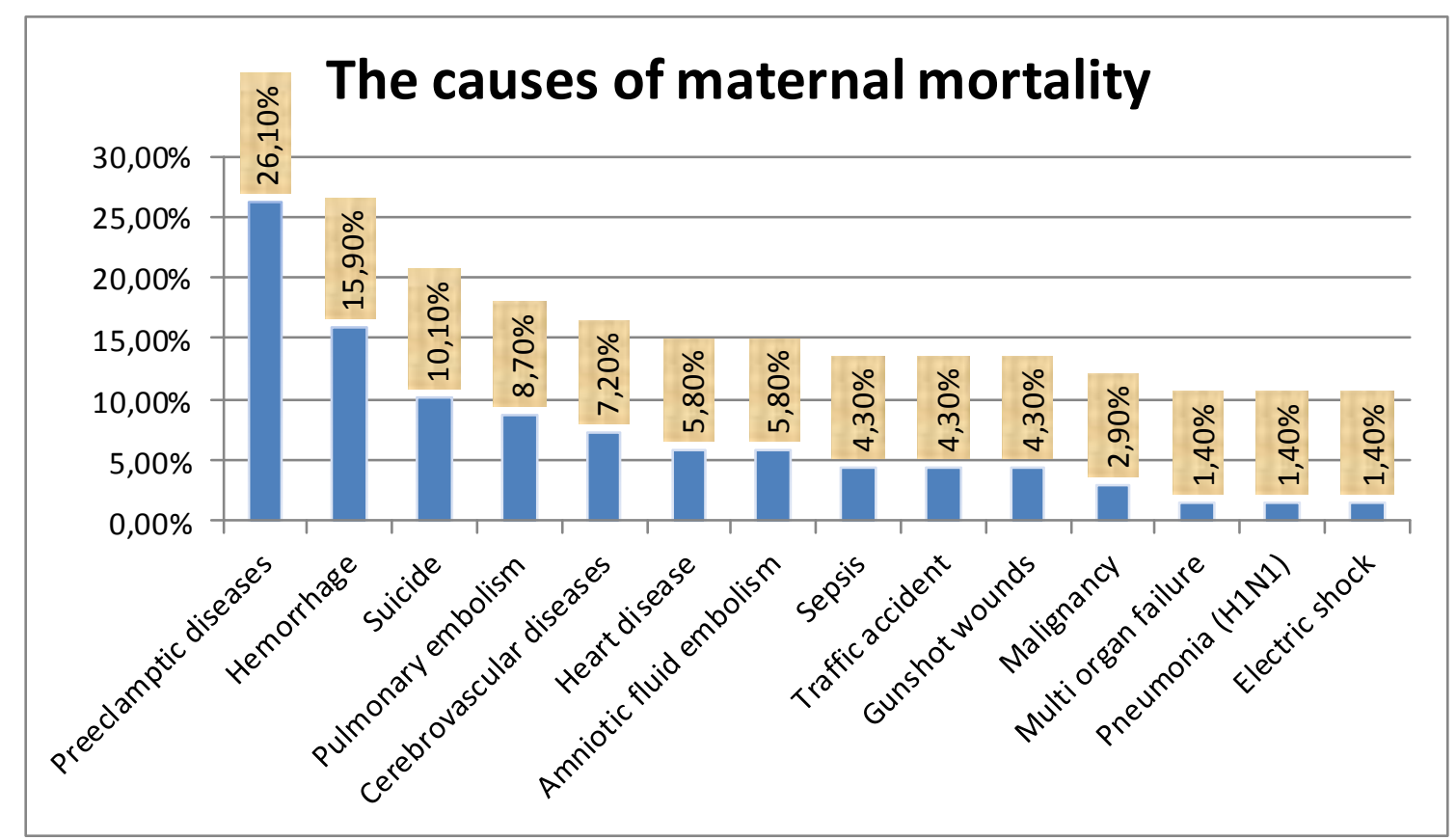

Fig. 6. The causes of maternal mortality.

The data are given in percent $(\%)$.

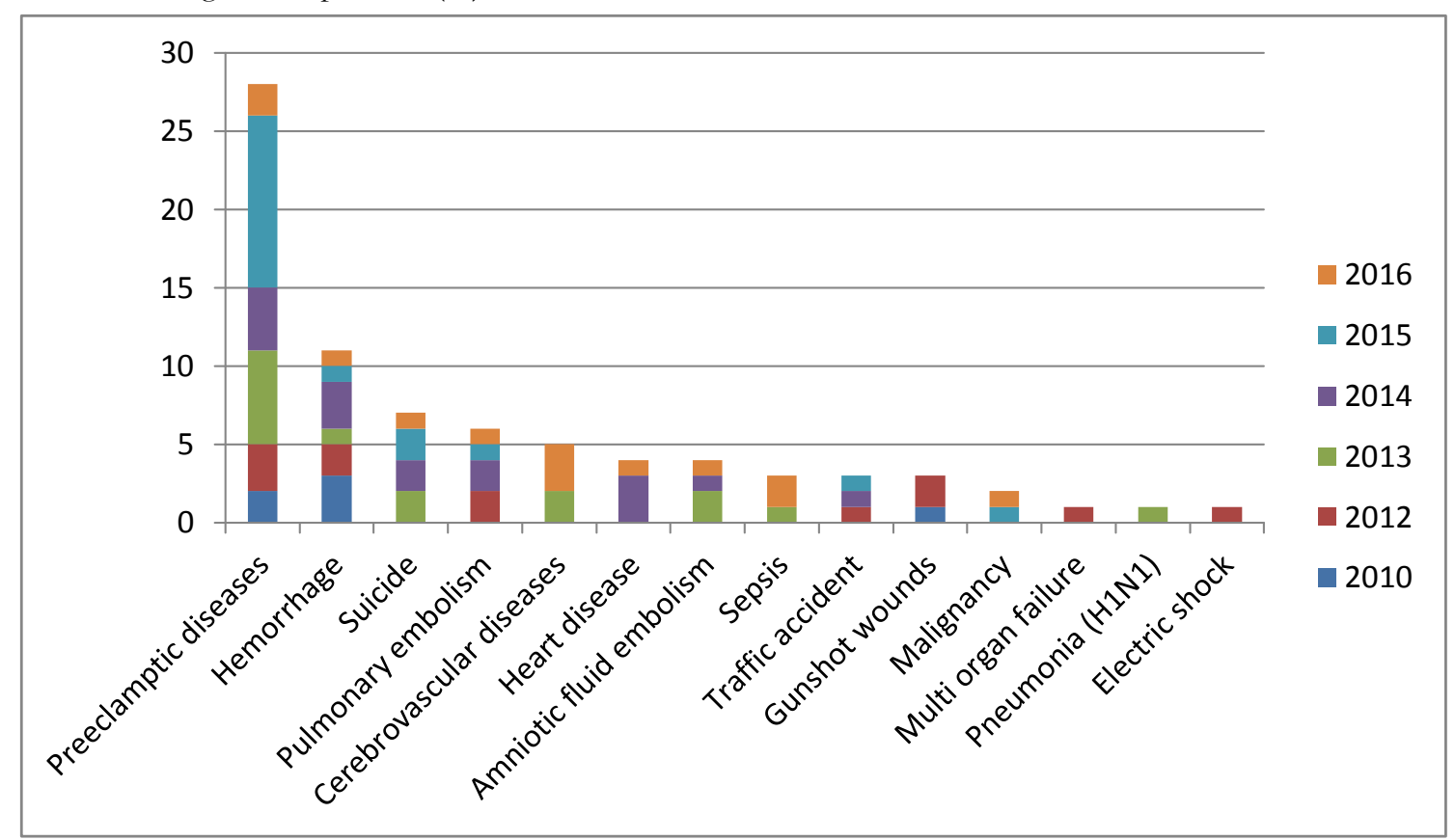

Fig. 7. Distribution of causes of maternal deaths by years.

The data are given in number.

When maternal mortality is examined in terms of the ending pregnancies, we found that $53.6 \%$ of cases were delivered with cesarean section, $27.5 \%$ were vaginal delivery, $1.4 \%$ had abortion and $17.4 \%$ had died when still pregnant. Creanga et al. (14) reported maternal mortality rate associated with pregnancy in the United States as 17 in 100.000 live births. They found that older age and race (increased risk in black women compared to white women) are associated with increased mortality. When maternal mortality and pregnancy outcomes are examined; they found that; $26.5 \%$ of cases were in antenatal period, $53.7 \%$ of cases were after live birth, $4.9 \%$ of cases were after stillbirth, $2.7 \%$ of cases were after ectopic pregnancy, $2.4 \%$ of cases were after spontaneous or induced abortion and maternal mortality after gestational trophoblastic disease was seen in 1 case. In the 
same study, pregnancy termination and death time of $86.8 \%$ of the cases were known; it was found that $30.5 \%$ of the deaths happened before birth, $16.8 \%$ were during the first day of birth or pregnancy termination, $18.2 \%$ were in postpartum 1-6 day, 21.3\% were in postpartum 7-41 days and $13.2 \%$ were in the postpartum day 42 or after.

When we examined the causes of death of the cases in general; preeclamptic diseases, hemorrhage, suicide and pulmonary embolism were the main causes of death (Figure 6). These reasons we identified were in line with the reasons found in the literature worldwide. In addition, when we examine the causes of death, we found that coincidental deaths were due to suicide, traffic accidents and firearm injuries frequently. We found that the causes of direct maternal death were most prevalent due to preeclamptic diseases in accordance with the literature, followed by hemorrhage and pulmonary embolism. We found that indirect causes of maternal death were caused by cerebrovascular diseases, heart diseases and sepsis as reported in the literature (Table 5).

In a study conducted in Scandinavian countries, where maternal mortality rate was one of the least in the world, the maternal mortality rate was found to be $6.6 / 100.000$. 54\% of these deaths were due to obstetric causes and $46 \%$ were due to indirect obstetric causes. When all causes of death were examined, heart diseases, preeclampsia, thromboembolism and suicides were among the first 4 causes. Among the causes of direct obstetric death were preeclampsia and thromboembolism, and indirect obstetric causes of death were heart diseases and suicides in the first place (15).

Generally, obstetricians give more importance to preeclampsia and hemorrhage, but they should also pay attention to suicidal events that may occur during pregnancy or postpartum period due to psychiatric problems. While doing routine obstetric and postpartum follow-ups, psychiatric evaluation should not be forgotten. Because these causes of death are preventable. According to CDC data, the maternal mortality rate for cardiovascular causes in pregnancy is 4.2-4.8 in 100000 live births (16). In their study of maternal mortality in the United States between 2011 and 2013, Creanga et al. (14) found that cardiovascular diseases was the leading cause of mortality $(15.5 \%)$ and $11 \%$ of patients with cardiomyopathy had died. In our country, Engin Üstün et al. (17) studied cardiac-induced maternal deaths and they found that maternal mortality rate as 19.7 in 100000 live births. Although the main cause of death of these cases was hemorrhage, while in $16.5 \%$ the main cause of death was due to cardiac causes and valvular heart disease $(25.6 \%)$ was the most common cause of cardiac disease. In the same study, they reported that hypertension $(13.2 \%)$, aortic aneurysm $(9.3 \%)$, pulmonary embolism (8.5\%) and ischemic heart disease $(8.5 \%)$ were among the leading causes of other heart diseases. In these cases, the increase in age is related to a high probability of mortality. In Turkey, it is suggested that the main cause of valvular heart diseases is rheumatic fever, which pregnancies should be performed after the treatment of the disease, follow-up with cardiologists from early gestation period and follow-up at a center with a high risk pregnancy unit.

Nair et al. (18) reported that cardiac diseases are the most common cause of maternal mortality due to indirect causes in England, followed by all sepsis events including pneumonia and influenza, and that also neurological diseases and other indirect reasons cause maternal mortality. We have detected pneumonia in one of our cases, due to the H1N1 virus, which is also common in our country in recent years, and that was the cause of death. Patients with respiratory disease (asthma, chronic bronchitis, etc.) should be carefully evaluated in terms of respiratory function when pregnant. In addition, patients who are in risk for pneumonia should be evaluated for vaccination.

Pregnancy increases hypercoagulability, stasis, and inactivity increase coagulation susceptibility. Among the causes of death of the cases pulmonary embolism was the fourth most frequent cause detected in all cases. Pulmonary embolism was the third most common cause of direct causes of maternal mortality. Pulmonary embolism is one of the life-threatening causes in pregnant women. Approximately $15 \%$ of maternal deaths in developed countries are due to pulmonary embolism (19). In a study conducted in our country, the maternal mortality rate due to pulmonary embolism was $7.5 \%$. In $29.4 \%$ of cases, pulmonary embolism was detected in antepartum period, $52.9 \%$ in postpartum period after cesarean operation and $11.7 \%$ in postpartum period after vaginal delivery. As a result of this study, they reported that cesarean birth, heart diseases and obesity are important risk factors for pulmonary embolism and that early diagnosis and treatment of pulmonary embolism, early mobilization and anticoagulant prophylaxis are important factors in reducing mortality associated with pulmonary embolism (20). 
When we studied the death time of our cases, we found that the mean time of death was $13.7 \pm$ 25.5 days. We found that deaths due to postpartum hemorrhage occurred within the first 48 hours of postpartum. Bleeding in the postpartum period usually occurs within the first 2 days. First two hours after bleeding is called as golden hours. Early diagnosis and early intervention in this period can mostly prevent deaths due to bleeding. In comparison to the cities around Van province, the city is in better condition due to its health infrastructure and facilities. The surrounding provinces and districts frequently refer patients to Van for further diagnosis and treatment. If necessary, after the initial interventions in risky cases patients should be referred to the tertiary center in time. Delays in the first intervention or referral of the patient to the tertiary center will increase the mortality rate. Marshall et al. (21) investigated the relationship between postpartum hemorrhage and the length of stay in the hospital; reported that $27.6 \%$ of the maternal mortalities in the hospital during the study period were due to direct postpartum hemorrhage. In this study, they found that maternal mortality rates were 3.2 / 100000 without postpartum hemorrhage, $19 / 100000$ due to postpartum hemorrhage by uterine atony and 103.5 / 100000 due to non-atonic postpartum hemorrhage. Patients with non-atonic postpartum hemorrhage among patients with maternal mortality were found to have been hospitalized longer than patients with atonic postpartum hemorrhage and those without hemorrhage. The authors stated that by applying optimal approaches to postpartum hemorrhage, maternal mortality and the length of stay in the hospital can be reduced.

In our study, we found that cases of hemorrhage were the second most common cause of death. In recent years, the Ministry of Health and the Gynecology and Obstetrics Associations have had serious training efforts to reduce mortality rates due to postpartum hemorrhage. There is good coordination and cooperation among the obstetricians working in Van. Hemorrhage-related death rates decreased, though, has not been completely prevented.

Khan et al. (22) found that hemorrhages (most commonly postpartum hemorrhage), infection (most commonly puerperal sepsis), organ dysfunction and anemia were among the major causes of maternal mortality in their studies of near miss and maternal mortality. In the same study, the authors found that near miss and maternal mortality were high in cases where delivery was not planned prenatally. Similarly, Maternal causes of death are multifactorial. In an analysis of maternal health in Ethiopia, demographic, behavioral, nutritional and health services-related negative factors were associated with negative maternal health outcomes. Beside that, among the important factors related to maternal mortality were low quality of birth facilities, inadequate health care providers, lack of emergency obstetric services, and inadequate and inappropriate referral for emergency obstetric care $(23-25)$.

The provision of standard emergency obstetric care in the south of Thailand has been shown to decrease maternal mortality. As a result of this practice, maternal mortality has been found to be significantly decreased by reducing the delay in seeking, reaching and accepting obstetric care (26). Situations like low socio-cultural and economic levels, lack of education, inadequate health care facilities and transportation, which cause delays in health care, have been classified as delay models. The first delay model is delay in deciding to receive health care. The second delay model is delay in applying for a health facility. The third delay model is delay in receiving quality health care services after applying for a health care provider (27).

When the maternal mortality time is examined, it is seen that the postpartum mortality rate is higher than the antepartum mortality rate. More than $2 / 3$ of maternal deaths occur after live birth, 14\% before birth, $12 \%$ after early pregnancy losses and $8 \%$ occur after stillbirth. It has been determined that deaths in the first 24 hours are more likely to occur in the cases reached the hospital $(28,10)$.

Hasegawa et al. (29) in a study which they investigated the maternal mortality found that $4 \%$ of first symptoms in first trimester, $8 \%$ in second trimester, $21 \%$ in third trimester, $27 \%$ in intrapartum period (19\% during vaginal birth, $8 \%$ during the cesarean operation) and 39\% had been in the postpartum period. Another study found that maternal deaths occurred in the first 48 hours in cases that could reach the hospital (11). The relationship between maternal mortality and pulmonary hypertension is mentioned in the literature and the mortality rate is up to $50 \%$ in these cases. In addition, medical conditions such as obesity, pregestational diabetes and chronic hypertension, which are common in the society, increase mortality rates. The risk of mortality is even higher in the case of superimposed preeclampsia or eclampsia, especially in the 
context of chronic hypertension. Advanced maternal age, regardless of education, parity and antenatal follow-up, contributes to increased mortality (30-32). The probability of maternal mortality increases 2.5 times in women aged 35-39 and 5.3 times in women aged 40 and over, compared with women aged 20 years (33).

In conclusion, maternal mortality is an important obstetric complication that needs attention. In Van, we have found that preeclamptic diseases are the most common cause of maternal mortality as stated in the literature. Good follow-up during pregnancy, pre-pregnancy and postpartum period will allow for early detection of cases entering the risk group, early diagnosis and treatment. The occurrence of cerebrovascular complications in preeclamptic patients increases the mortality rates. In recent years, hemorrhagic mortality rates have been reduced in developed countries, but remain an important cause in developing countries. In cases of postpartum hemorrhage, early diagnosis and early intervention, transfusion of blood and blood products are the most important steps to reduce mortality. All maternal candidates and pregnant women should be followed carefully before pregnancy, during pregnancy and postpartum period, early diagnosis should be done early in cases of maternal mortality.

\section{References}

1. International Statistical Classification of Diseases and Related Health Problems 10th Revision (ICD -10), WHO Version for 2016.

2. Knight M, Tuffnell D, Kenyon S, Shakespeare J, Gray R, Kurinczuk JJ (Eds.). On behalf of MBRRACEUK. Saving lives, improving mothers' care - Surveillance of maternal deaths in the UK 2011-2013 and lessons learned to inform maternity care from the UK and Ireland confidential enquiries into maternal deaths and morbidity 2009-2013. Oxford: National Perinatal Epidemiology Unit, University of Oxford, 2015.

3. http://www.who.int/gho/maternal_health/mor tality/maternal_mortality_text/en/

4. Alkema L, Chou D, Hogan D, et al. Global, regional, and national levels and trends in maternal mortality between 1990 and 2015, with scenario-based projections to 2030: a systematic analysis by the UN Maternal Mortality Estimation Inter-Agency Group. Lancet 2016; 387: 462-474.

5. United Nations. The Millennium Development Goals Report 2015. New York: United Nations; 2015.
6. Say L, Chou D, Gemmill A, et al. Global causes of maternal death: a WHO systematic analysis. Lancet Glob Health 2014; 2: 323-333.

7. Turkyilmaz AS, Koc I, Schumacher R, Campbell OM. The Turkey national maternal mortality study. The European Journal of Contraception \& Reproductive Health Care 2009; 14: 75-82.

8. World Health Organization. The WHO application of ICD-10 to deaths during pregnancy, childbirth and the puerperium: ICDMM. Geneva: World Health Organization, 2012.

9. www.tuik.gov.tr

10. Idoko P, Anyanwu MO, Bass S. A retrospective analysis of trends in maternal mortality in a Gambian tertiary health centre. BMC Res Notes 2017; 10: 493.

11. Obiechina Nj, Okolie V, Okechukwu Z, et al. Maternal mortality at Nnamdi Azikiwe University Teaching Hospital, Southeast Nigeria: a 10-year review (2003-2012). Int J Womens Health 2013; 5: 431-436.

12. Tessema GA, Laurence CO, Melaku YA, et al. Trends and causes of maternal mortality in Ethiopia during 1990-2013: findings from the Global Burden of Diseases study 2013. BMC Public Health 2017; 17: 160.

13. Qin M, Zhu R, Du L, Lu J, Xu HQ, Zhu LP. Analysis of maternal deaths in Shanghai from 1996 to 2015. Zhonghua Fu Chan Ke Za Zhi 2017; 52: 386-391.

14. Creanga AA, Syverson C, Seed K, Callaghan WM. Pregnancy-Related Mortality in the United States, 2011-2013. Obstet Gynecol 2017; 130: 366-373.

15. Vangen S, Bødker B, Ellingsen L, et al. Maternal deaths in the Nordic countries. Acta Obstet Gynecol Scand 2017; 96(9): 1112-1119.

16. Centers for Disease Control and Prevention. Pregnancyrelated mortality surveillance. Available at: http://www.cdc. gov/reproductivehealth/MaternalInfantHealth PMSS.html. Retrieved December 21, 2016.

17. Engin-Üstün Y, Çelen Ş, Özcan A, et al. Maternal mortality from cardiac disease in Turkey: a population-based study. J Matern Fetal Neonatal Med 2012; 25: 2451-2453.

18. Nair M, Nelson-Piercy C, Knight M. Indirect maternal deaths: UK and global perspectives. Obstet Med 2017; 10: 10-15.

19. Khan KS, Wojdyla D, Say L, Gulmezoglu AM, Van Look PF. Who analysis of causes of maternal death: a systematic review. Lancet 2006; 367: 1066-1074.

20. Sanisoğlu S, Uygur D, Keskinkıliç B, et al. Maternal mortality cases from pulmonary embolism: A nation-wide study in Turkey. J Obstet Gynaecol 2017; 37: 151-156. 
21. Marshall AL, Durani U, Bartley A, et al. The impact of postpartum hemorrhage on hospital length of stay and inpatient mortality: a National Inpatient Sample-based analysis. Am J Obstet Gynecol 2017; 217: 344.e1-344.e.6.

22. Khan T, Laul P, Laul A, Ramzan M. Prognostic factors of maternal near miss events and maternal deaths in a tertiary healthcare facility in India. Int J Gynaecol Obstet 2017; 138: 171-176.

23. UNFPA. Trends in Maternal Healthin Ethiopia: Challenges in achieving the MDG for maternal mortalityIndepth Analysisof the EDHS 20002011. Addis Ababa: UNFPA; 2012.

24. Austin A, Gulema H, Belizan M, et al. Barriers to providing quality emergency obstetric care in Addis Ababa, Ethiopia: Healthcare providers' perspectives on training, referrals and supervision, a mixed methods study. BMC Pregnancy Childbirth 2015; 15: 74.

25. Admasu K, Haile-Mariam A, Bailey P. Indicators for availability, utilization, and quality of emergency obstetric care in Ethiopia, 2008. Int J Gynaecol Obstet 2011; 115(1): 101105.

26. Liabsuetrakul T, Peeyananjarassri K, Tassee S, Sanguanchua S, Chaipinitpan S. Emergency obstetric care in the southernmost provinces of Thailand. Int J Qual Health Care 2007; 19: 250256.
27. Thaddeus S, Maine D. Too far to walk: maternal mortality in context. Soc Sci Med 1994; 38: 1091-1110.

28. Berg CJ, Chang J, Callaghan WM, Whitehead SJ. Pregnancy-related mortality in the United States, 1991-1997. Obstet Gynecol 2003; 101: 289-296.

29. Hasegawa J, Sekizawa A, Tanaka H, et al.; Maternal Death Exploratory Committee in Japan; Japan Association of Obstetricians and Gynecologists. Current status of pregnancyrelated maternal mortality in Japan: a report from the Maternal Death Exploratory Committee in Japan. BMJ Open 2016; 6: e010304.

30. Kahn ML. Eisenmenger's syndrome in pregnancy. N Engl J Med 1993; 329: 887.

31. Berg CJ, Callaghan WM, Syverson C, Henderson Z. Pregnancy related mortality in the United States, 1998 to 2005. Obstet Gynecol 2010; 116: 1302-1309.

32. Campbell KH, Savitz D, Werner EF, et al. Maternal morbidity and risk of death at delivery hospitalization. Obstet Gynecol 2013; 122: 627-633.

33. Chang J, Elam-Evans LD, Berg CJ, et al. Pregnancy-related mortality surveillance-United States, 1991-1999. MMWR Surveillance Summary 2003; 52: 1-8. 